Int. J. Morphol.,

33(4):1323-1332, 2015.

\title{
Improved Sectioned Images and Surface Models of the Whole Female Body
}

\author{
Mejoramiento de Imágenes Seccionadas y Modelos de Superficie del Cuerpo Femenino Completo
}

\author{
Hyo Seok Park*; Dai Hai Choi** \& Jin Seo Park*
}

PARK, H. S.; CHOI, D. H. \& PARK, J. S. Improved sectioned images and surface models of the whole female body. Int. J. Morphol., 33(4):1323-1332, 2015.

SUMMARY: The objective of this research was to present high-quality sectioned images of a whole female body which would be helpful in creating an atlas, virtual dissection, and various applications for medical education and clinical trial. In addition, the authors sought to demonstrate the applicabilities of sectioned images. A female cadaver was ground serially using the cryomacrotome and photographed to make the sectioned images. Structures in the images were segmented to produce segmented images in Photoshop. In the self-developed browsing software, the sectioned and segmented images were stored. Based on the segmented images, surface models were built on commercial software and saved as PDF file. High-quality sectioned images of the female body were taken (intervals, 0.2 $\mathrm{mm}$ or $1 \mathrm{~mm}$; pixel size, $0.1 \mathrm{~mm}$; color depth, 48 bit color). In the images obtained, very small and complicated structures could be identified in color of living body. In order to ascertain the applicability of the images, the browsing software including sectioned and segmented images and the PDF file including surface models were produced. The sectioned images and surface models produced during this research will prove to be a useful source for medical software. All data generated is available free of charge.

KEY WORDS: Whole body imaging; Cross sectional anatomy; Female; Three-dimensional imaging; Visible Human Project.

\section{INTRODUCTION}

Sectioned images of the human body are of considerable use due to their high resolutions and natural colors as compared with computer tomographs (CT) and magnetic resonance images (MRIs) (Ackerman, 1999; Dai et al., 2012). Available images include those of the Visible Human Project (VHP; male and female) conducted in the United States (Ackerman; Spitzer et al., 1996, 1998; Spitzer \& Whitlock, 1998); the Chinese Visible Human (CVH; male and female) (Zhang et al., 2006) and the Virtual Chinese Human (VCH; male and female) (Tang et al., 2010; Yuan et al., 2008); and the Visible Korean (VK; male whole body, male head, and female pelvis) (Park et al., 2005a, 2009; Shin et al., 2013) (Table I). Male sectioned images of the VHP, $\mathrm{CVH}$, and VK were used in many ways; for example, for creating atlases (Cho, 2009; Spitzer et al., 1998), browsing software (Shin et al.; Shin et al., 2011, 2012a), and virtual dissection software (Schiemann et al., 2000; Spitzer \& Scherzinger, 2006), and provided the facility of free access to three dimensional (3D) models in PDF files atlases (Shin et al., 2012b; Park et al., 2013). Furthermore, the sectioned images of VK were used that the dose conversion coefficients of radiology were calculated virtually (Kim et al., 2008).

However, the usefulnesses of female-sectioned images prepared were limited for the following reasons. In VHP images, degeneration was observed in the uterus and ovaries because the subject was post-menopausal (59 years old), and the lateral sides of both arms were not shown because the subject was obese. In addition, image quality was not good because of the limited performances of the digital camera and personal computer used (Spitzer et al., 1996, 1998). At some websites, digital atlases of the VHP female images could be shown (http://vhp.med.umich.edu/ RegionalB.html). However, the shortcomings of the images appeared in the digital atlases. Furthermore, the digital atlases could not downloaded, and therefore user could be accessed easily at anytime and anywhere in case of off-line. In $\mathrm{CVH}$ and VCH images, images of small pixel size $(>0.1 \mathrm{~mm})$ and

\footnotetext{
* Department of Anatomy, School of Medicine, Dongguk University, Gyeongju, Republic of Korea.

** Department of Emergency Medicine, School of Medicine, Dongguk University, Gyeongju, Republic of Korea.

This work (2012R1A2A2A01012808) was supported by Mid-career Researcher Program through NRF grant funded by the MEST.
} 
Table I. Comparison of female body sectioned images produced of each country.

\begin{tabular}{lcccc}
\hline S ectioned images & Age & Intervals $\mathbf{( m m})$ & Pixel size (mm) & Drawback \\
\hline Visible Human Project & 59 & 0.33 & 0.33 & Obese, menopausal \\
Chinese Visible Human & 22 & $0.25-0.5$ & $0.1-1$ & Embalmed, dyed \\
& 21 & 0.1 & --- & Embalmed, dyed \\
& 25 & 0.2 & 0.2 & Embalmed, dyed \\
Virtual Chinese Human & 19 & 0.2 & 0.2 & Embalmed, dyed \\
Visible Korean & 43 & 0.1 & 0.1 & Only pelvis \\
\hline
\end{tabular}

24 bit color were made, but living body colors could not be shown because fixative was injected into the body and red dye perfused into arteries (Yuan et al.; Zhang et al.), and the VK provided no sectioned images of the whole female body (Table I). If there were high quality sectioned images of whole female body, the images would use very useful in many ways like male images.

The aim of this research was to present improved sectioned images of an adult female that show almost all body structures in living body color. In addition, we sought to demonstrate the usefulness of the sectioned images produced for medical education and clinical trials. In order to achieve these aims, serial sections of the whole body of an adult female cadaver were prepared and photographed. For showing the high-qualities of the sectioned images to readers, some images were inserted in this paper. In addition, sectioned images were segmented and reconstructed to produce browsing software and a 3D PDF file.

\section{MATERIAL AND METHOD}

The subject was a Korean female cadaver aged 26 years of standard body size (length, 1,690 mm; weight, 52 kg) (Fig. 1a). After receiving consent from the family of the deceased, the cadaver was scanned by computerized tomography machine using a Philips Brilliance 64 channel CT scanner for pathological findings (Table II), and then frozen at $-70{ }^{\circ} \mathrm{C}$ to prevent decay during a week. After the frozen female cadaver with embedding agent ( $3 \%$ gelatin solution containing $0.5 \%$ methylene blue) were put into an embedding box, the embedding box was refrozen at $-70^{\circ} \mathrm{C}$.
For serial sectioning of the cadaver, a cryomacrotome was used. The cryomacrotome used (width, $3 \mathrm{~m} x$ height, $4 \mathrm{~m}$ $\mathrm{x}$ length $5 \mathrm{~m}$; 15 ton; HanwonTM of Republic of Korea) with a moving error of $0.001 \mathrm{~mm}$ enabled the whole body to be serially ground at a constant thickness, as previously described (Park et al., 2005b). Using the cryomacrotome, the frozen embedding box containing the cadaver was ground at $0.2 \mathrm{~mm}$ (from the vertex of the head and perineum; upper body) or at $1.0 \mathrm{~mm}$ intervals (from under the perineum to the toes; lower body) to produce sectioned surfaces. After grinding, frost was removed using $10 \%$ ethyl alcohol and protruding dense connective tissues were trimmed with a scalpel.

For photographing of the sectioned surfaces, a high performance digital camera $\left(\right.$ Canon $^{\mathrm{TM}}$ EOS-1Ds Mark III ${ }^{\mathrm{TM}}$ equipped with a Canon ${ }^{\mathrm{TM}}$ EF 50mm f/1.2L USM lens) was used. This camera incorporated Canon's newest CMOS 21.1 megapixel (effective) image sensor. The digital camera was located in front of the cryomacrotome, and two strobes (Digital S, Elinchrom ${ }^{\mathrm{TM}}$ ) connected to a power pack (Digital 2, Elinchrom ${ }^{\mathrm{TM}}$ ), were positioned alongside the digital camera. The sectioned surfaces were photographed using the digital camera (ISO, 100; shutter speed, 1/200; aperture opening 9.0; manual focus). Images were checked and saved as in tagged image file format (TIFF) in Photoshop CS5 version 12 (Adobe Systems, Inc., San Jose, CA, USA) at a resolution of $5,616 \times 3,744$. By repeating the procedure sectioned images of the whole body were obtained (Figs. 2 and 3, Table II).

The next stage required post-processing of the sectioned images. Original images were re-sectioned on a personal computer to produce coronal and sagittal images using self developed software (Park et al., 2010). The coronal

Table II. Features of CT, sectioned images, and segmented images.

\begin{tabular}{|c|c|c|c|c|c|c|c|c|}
\hline Images & Region & Resolution & Number & $\begin{array}{c}\text { Intervas } \\
(\mathbf{m m})\end{array}$ & $\begin{array}{c}\text { Pixel size } \\
(\mathbf{m m})\end{array}$ & Color depth & $\begin{array}{c}\text { One } \\
\text { file size }\end{array}$ & $\begin{array}{c}\text { Total } \\
\text { file size }\end{array}$ \\
\hline$\overline{\mathrm{CT}}$ & Whole body & $512 \_512$ & 1,642 & 1.0 & 1.0 & 8 bit gray & $257 \mathrm{~KB}$ & $442 \mathrm{MB}$ \\
\hline \multirow{2}{*}{ Sectioned images } & Upper body* & $5,616 \times 3,744$ & 4,116 & 0.2 & 0.1 & 48 bit color & $120 \mathrm{MB}$ & $484 \mathrm{~GB}$ \\
\hline & Lower body ${ }^{\S}$ & $5,616 \times 3,744$ & 819 & 1.0 & 0.1 & 48 bit color & $120 \mathrm{MB}$ & $96 \mathrm{~GB}$ \\
\hline Segmented images & Whole body & $5,616 \times 3,744$ & 1,642 & 1.0 & 0.1 & 8 bit color & $20 \mathrm{MB}$ & $32 \mathrm{~GB}$ \\
\hline
\end{tabular}

File format of all images was TIFF. * = Images of from the vertex of the head to perineum. $\S=$ Images from under the perineum to toe. 

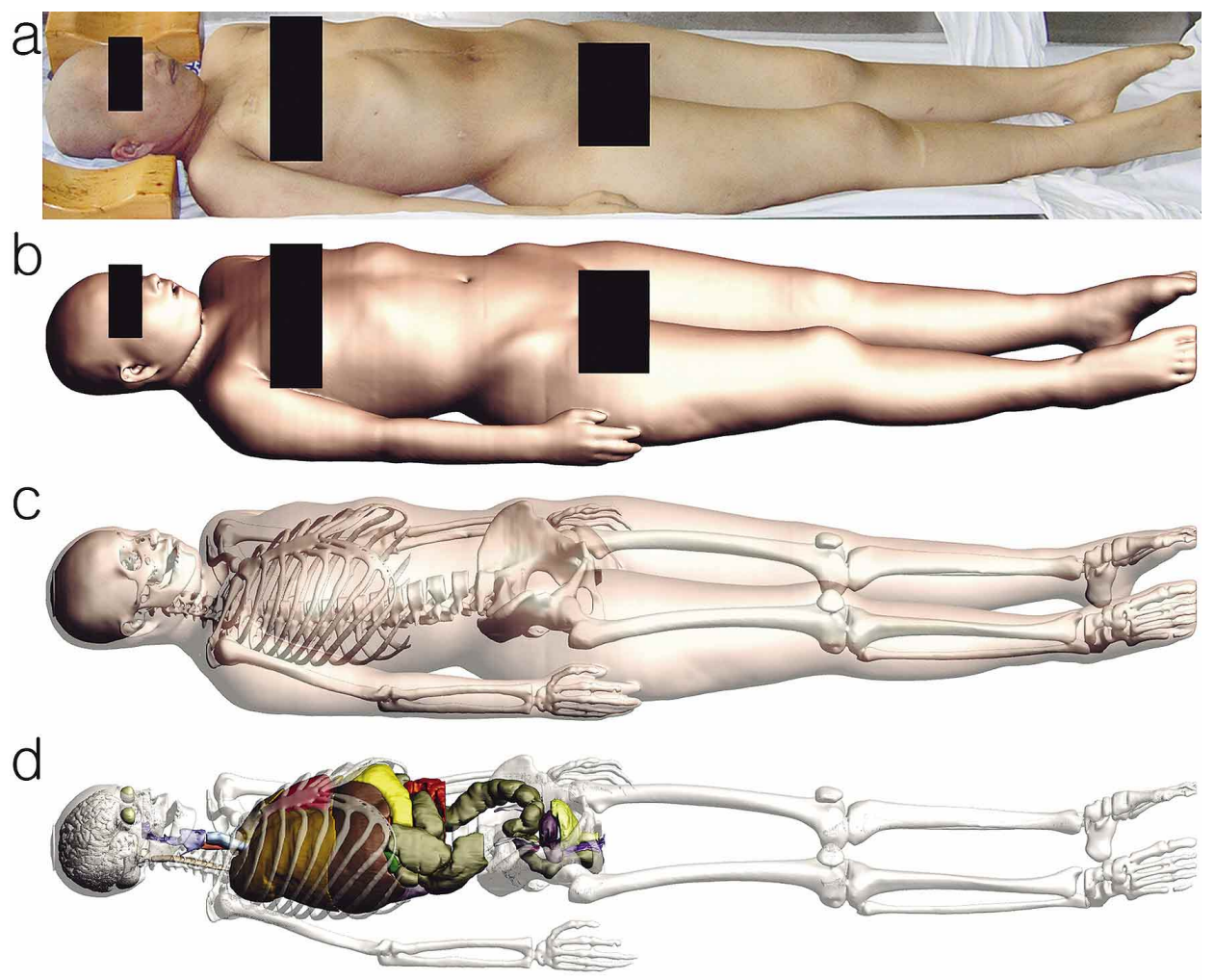

Fig. 1. a) Korean female cadaver and b) surface models. Real body shape is identical with a skin surface model constructed using the sectioned and segmented images. c) Semitransparent skin with inner organs and d) semitransparent bone with inner organs are shown through surface models in the PDF file. and sagittal images were then used to identify inconsistent alignments and brightness levels, and original images with the problems were revised using the 'move' and 'Fourier transform' commands in Photoshop.

Twenty-seven structures were chosen for segmentation (Table III). After selecting sectioned images at $1 \mathrm{~mm}$ intervals, the boundaries of selected structures were outlined using the lasso or magnetic lasso tools in Photoshop, and the outlined structures were then filled with specific colors (Park et al., 2005b; Park et al., 2010). Structure name, and red, green, blue values constituting the color about every color-filled structure were saved as color.txt. Using this method, 1,642 segmented images of 27 structures were obtained (resolution 5,616 x 3,744, color depth 8 bit; file format TIFF).

We used browsing software that was previously developed using the $\mathrm{C \#}$ language of Microsoft Visual Studio.NET 2003 (Microsoft Corporation, Redmond, WA) composed of operating files with color.txt and image folders. The sectioned and segmented images were put into the soft-

Table III. Twenty seven structures in the female body were segmented in sectioned images and reconstructed to build surface models.

\begin{tabular}{ll}
\hline System & Structures \\
\hline Skeletal & Bones \\
Alimentary & Pharynx, Esophagus, Stomach, Small intestine, Large intestine, Liver, Gallbladder \\
Muscular & Muscles \\
Respiratory & Larynx, Trachea, Lungs \\
Urinary & Kidneys, Urinary bladder, Female urethra \\
Genital & Ovaries, Uterine tubes, Uterus, Vagina \\
Cardiovascular & Heart \\
Lymphoid & Spleen \\
Nervous & Spinal cord, Cerebrum, Cerebellum, Brainstem \\
Sensory & Eyeballs \\
Integumentary & Skin \\
\hline
\end{tabular}


ware. If a user located the mouse pointer on a structure in sectioned or segmented images, name of the structure was seen as pop-up text (Park et al., 2013; Shin et al.; Shin et al., 2011, 2012b). In order to distribute the browsing software on-line, its file size was reduced by lowering the resolution of sectioned and segmented images from 5,616 x 3,744 to $1,000 \times 410$. Furthermore, sectioned and segmented images representing $1.0 \mathrm{~mm}$ intervals were then stored in appropriate image folders. Operating files and new image data were then combined together using the Nullsoft Scriptable Install System of NSIS Media to produce an installation file (Fig. 4a).
Based on the segmented images, surface models of the segmented structures were built (Table III) on Mimics version 10.01 (Materialise, Leuven, Belgium). In the Mimics, a structure equivalent to a color in all segmented images was extracted, stacked, and reconstructed by surface modeling to create a surface model. In the same manner, other structures were reconstructed (Shin et al., 2009, 2013). After checking the shapes of the surface models, they were saved as stereolithography (STL) files. Each structure in each STL file was then gathered and saved as a portable document format (PDF) file using 3D Reviewer accompanying software of Acrobat 9.0 Pro Extended. When the PDF file was
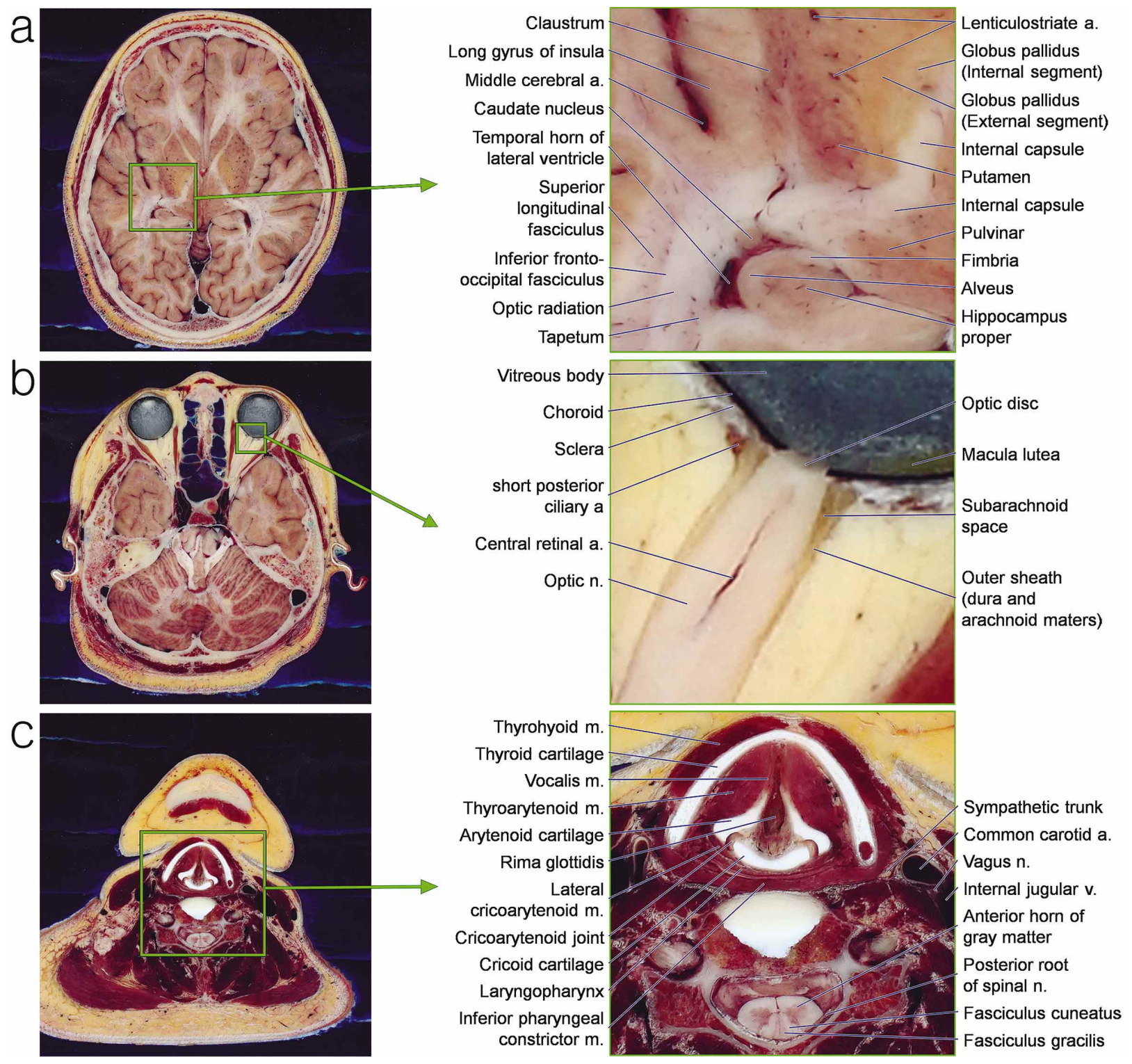

Fig. 2. Sectioned images and magnified images of the head and neck. a) Basal nuclei, limbic system, and tracts of white matter in cerebrum are shown. b) The optic nerve is coated with meninges and the central retina artery passes the optic nerve. c) The larynx consisted with cartilages and muscles and each funiculus in the spinal cord is shown. 

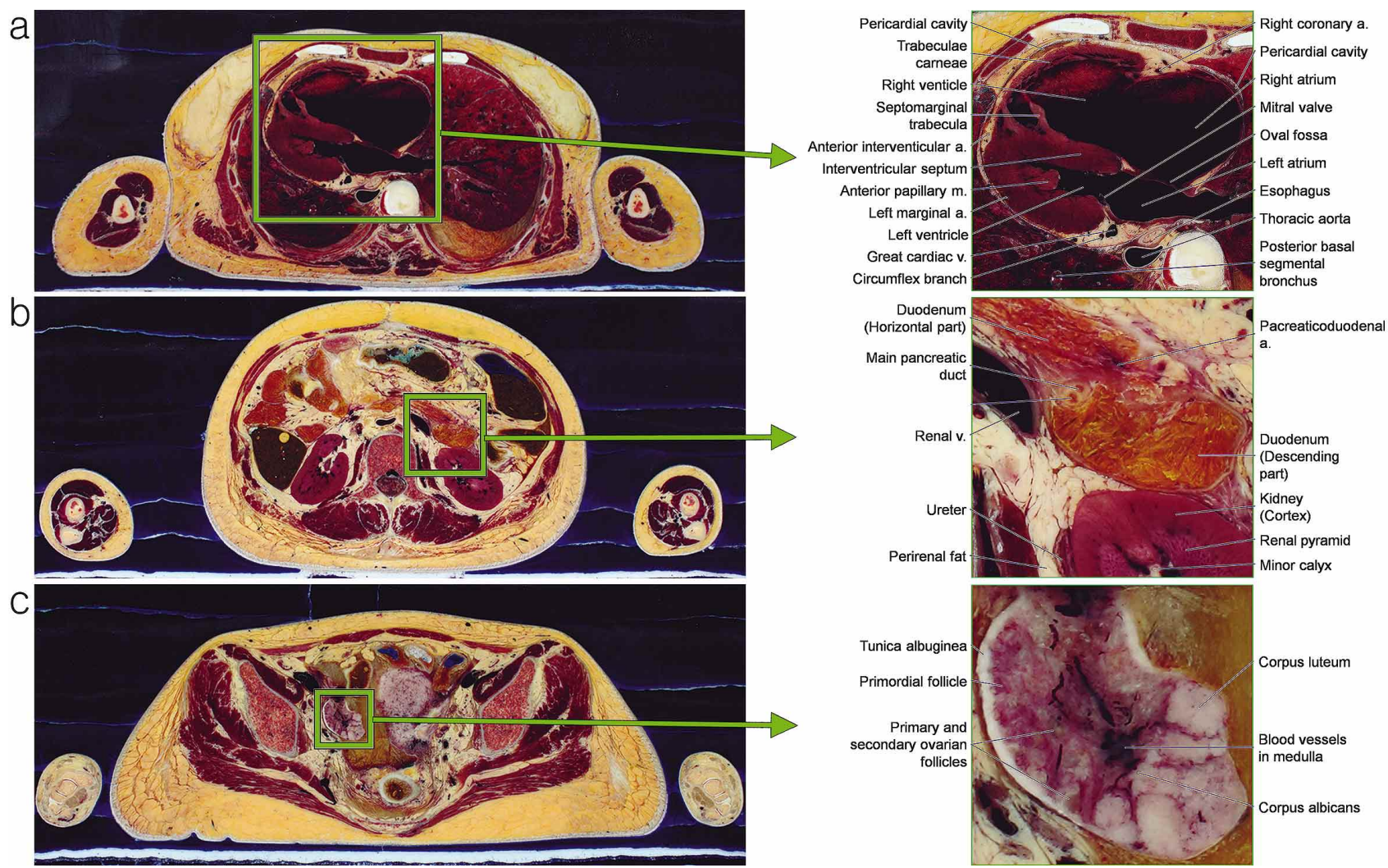

Fig. 3. Sectioned images and magnified images from thorax to pelvis (a., artery; v., vein; n., nerve; m., muscle). a) The four heart chambers consist of atriums and ventricles can be observed in an image of the thorax. b) Inner duodenum of the abdomen, the pancreatic duct is opened and c) an ovary in the pelvis is shown.

opened on Adobe Reader, the anatomical terms were displayed in the model tree window (Figs. 1 and $4 \mathrm{~b}$ ) (Park et al., 2013; Shin et al., 2012b).

\section{RESULTS}

A total of 1642 CT scans of the whole cadaver were taken and carefully examined (Table II). Although the subject died of stomach cancer and pneumonia, stomach and lung shapes were relatively normal because she did not undergo surgery. Furthermore, her reproductive structures were normal for a 26-year-old.

We prepared 4,116 sectioned images (pixel size 0.1 $\mathrm{mm}$ ) at $0.2 \mathrm{~mm}$ intervals of the upper body from the vertex of the head to the perineum; 819 images were prepared at $1 \mathrm{~mm}$ intervals of the lower body from under the perineum to the toes. A total of 4,935 sectioned images of the whole body were prepared (an image file size, $120 \mathrm{MB}$; total file size, 580 GB; color depth, 48 bit color) (Figs. 2 and 3, Table II).
The sectioned images produced are of better image quality than those produced during previous studies, including VHP, CVH, and VCH (Spitzer et al., 2008; Yuan et al.). The high quality of the sectioned images was described through the following examples.

In the cerebrum, the alveus and fimbria of hippocampus are nerve fibers (white matter), and thus, appear light. The hippocampus proper has many cell bodies (gray matter) and has a strong reddish color (Fig. 1a).

In the eyeball, the three layers, retina, choroid, and sclera, are observed. In the living body, a retina is naturally transparent, and therefore, cannot be seen. However, in a cadaver, the fibrous tissue of the retina is denatured, and thus, was semi-transparent. At the posterior chamber of the eyeball, the blind spot is observed as the optic disc created by the absence of retina, choroid, and sclera. The macula lutea lies lateral to the optic disc (Fig. 2b).

In bilateral edges of the optic nerve, meninges (pia mater) of dark color lines were apparent. In the junction between the eyeball and optic nerve, the subarachnoid space 
is observed as an expanded space. In the inner optic nerves, the central retinal arteries supply blood to the eyeballs and are observed. In head images, the entire course of ophthalmic arteries was traced from the internal carotid artery to central retinal artery in orbit (Fig. 2b).

In the larynx, cartilage and muscles are clearly observed due to their white and dark-red colors, respectively. Thyrohyoid muscle is attached in front of thyroid cartilage, and at its posterior, thyroarytenoid muscle pulls the arytenoid cartilage anteriorly. This cartilage is connected to cricoid cartilage by the lateral cricoarytenoid muscle. Furthermore, the space between the bilateral vocalis muscles is occupied by the rima glottidis (Fig. 2c).

At the vertebral foramen of the cervical vertebra, gray and white matters of the spinal cord are clearly identified. In gray matter, the anterior horn is larger than the posterior horn because this region is at the sixth cervical segment of the spinal cord, which includes many motor neurons of the brachial plexus. In the white matter, anterior, lateral, and posterior funiculi are distinctly divided. Each funiculus is shown in detail; for example, the fasciculus gracilis and fasciculus cuneatus are distinguishable in the posterior funiculus (Fig. 2c).

In the heart, atria and ventricles are evident. The oval fossa appears as a thin wall between the atria. In the right ventricle, trabeculae carneae and a larger septomarginal trabecula are observed at the inner wall of the interventricular septum. The mitral valve is located between the left atrium and left ventricle. The wall of the left ventricle is thick due to a large amount of myocardium. Beyond the heart, coronary arteries are wrapped by a visceral layer of serous pericardium and frozen serous fluid of the pericardial cavity is observed in pericardium (Fig. 3a).

The duodenum is divided into four parts in sectioned images. The orifices of the main pancreatic duct and the bile duct of pancreas are present in its descending portion. The cortex and medulla of the kidney are distinct (Fig. 3b).

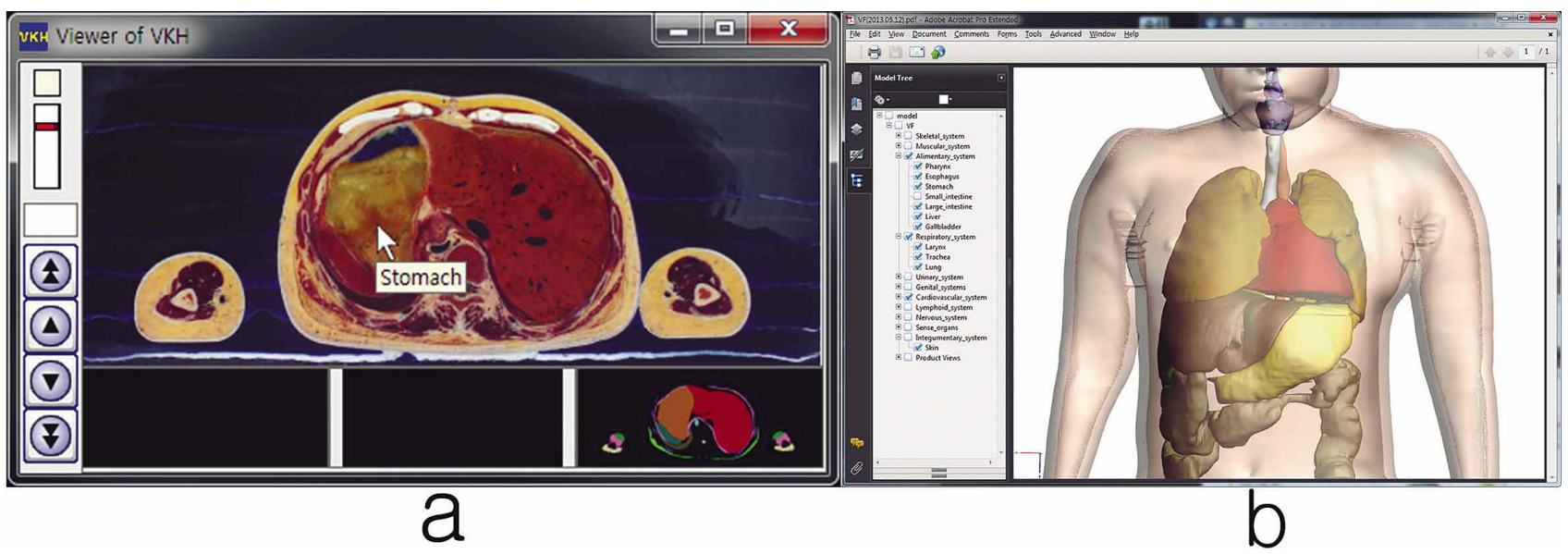

Fig. 4. Applications based on sectioned images and surface models. Using browsing software, sectioned images and segmented images are browsed; a) the names of structures appear as text tips. b) Surface models can be freely explored using the PDF file.

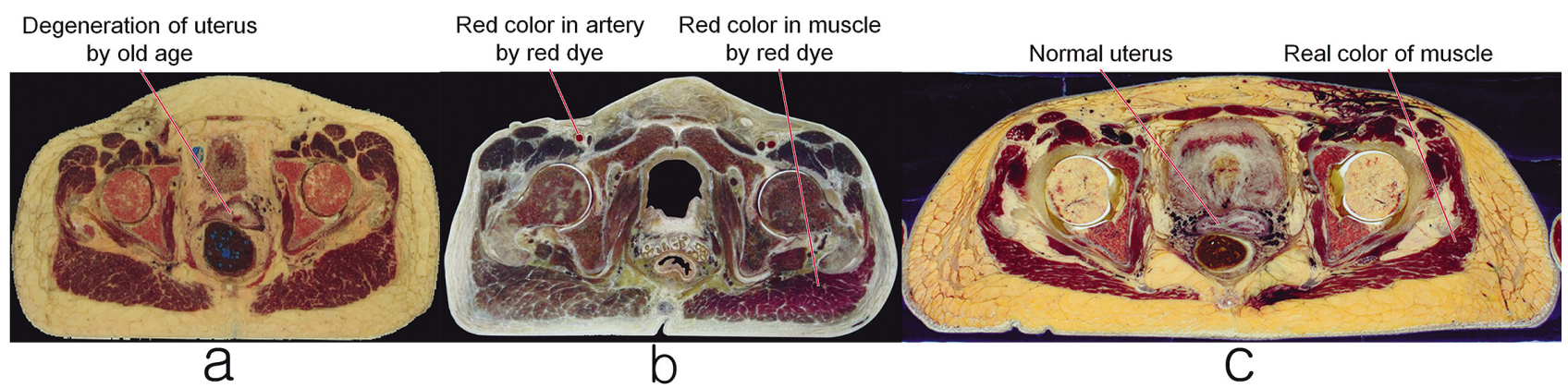

Fig. 5. Female sectioned images of Visible Human Project (VHP) and Chinese visible Human (CVH), and the present study. a) In the VHP image, degeneration of the genital organs due to an advanced age is evident. b) This CVH image shows a change in color caused by the injection of fixative and red dye. c) An image produced during the present study showing structures, including genital organs, at high definition in true color. 
In the ovary, white colored tunica albuginea surrounded the cortex. Primary and secondary follicles are identified through follicles had an antrum. The corpus luteum is localized in the cortical region. Wrinkles are observed around the corpus luteum because of collapse and folding of the walls of mature follicles after ovulation. The corpus albicans is observed near the corpus luteum (Fig. 3c).

To assess the applicability of the sectioned images, we produced browsing software and PDF file. This software allowed sectioned images and correspondence with segmented images to be browsed continuously and freely. When a mouse pointer is placed over a structure in sectioned or segmented images, the name of the structure appears as a text tip (Fig. 4a). In PDF file, the surface models of the 27 structures can be explored freely using a mouse drag on Adobe Reader version 9 and higher (Fig. 4b). In addition, we confirmed that skin surface models matched cadaver photographs (Fig. 1).

In addition to the above-mentioned structures, smaller, more complicated structures can also be identified in sectioned images. However, we cannot describe all structures in detail here, and therefore, the reader is invited to use the browsing software, which includes images (970 MB) and a PDF file including the surface models (229 MB), available on-line and free of charge at our homepage (anatomy.dongguk.ac.kr/ female/). If sectioned images of the original size be required (Figs. 2 and3), a hard disc (>1 TB) should be forwarded due to the sizes of the original images (Table II).

\section{DISCUSSION}

Sectioned images of the human body are invaluable. In anatomy, they have been used as a 2D atlas for sectional anatomy (Shin et al., 2011; Spitzer et al., 1998) or as a 3D atlas for virtual dissection (Park et al., 2013; Schiemann et al.; Shin et al., 2012b; Yuan et al.). In radiology, they are used as an instructive atlas for the accurate interpretation of CT and MRIs (Cho; Spitzer et al., 1998), and in neurology, as a coordinate system atlas for brain stereotactic surgery (Cho; Cho et al., 2012; Park et al., 2010). Furthermore, they are useful in many other areas of medicine (Park et al., 2006; Spitzer \& Scherzinger). However, almost all applications by VHP, $\mathrm{CVH}, \mathrm{VCH}$, and VK use mainly male images because of defects of the female images (Table I). Therefore, we undertook to produce state-of-art sectioned images of the whole adult female body (Figs. 2, 3 and 4).

To obtain high-quality images, small pixel size and deep color depth are necessary, and furthermore various conditions have to harmonize with each other. If only the pixel size and color depth are contemplated, image quality of $\mathrm{CVH}$ and $\mathrm{VCH}$ must be high (Yuan et al.), but their images were not high because other conditions were not enough (Fig. 5). Therefore, to produce high-quality sectioned images better than those produced in VHP, $\mathrm{CVH}$, or VCH, we tried that not only pixel size and deep color but also various conditions were satisfied as follows.

First, we experimented on the cadaver without any treatment in order to produce sectioned images with living body color. In VHP, $\mathrm{CVH}$, and $\mathrm{VCH}$, in order to prevent decay and to show small arterial networks, formalin or red dyes were injected into the cadavers respectively, and thus, tissue color were altered (Fig. 5a and 5b) (Spitzer et al., 1998; Yuan et al.; Zhang et al.). Therefore, in the present study, to prevent decay of the cadaver without formalin, it was frozen immediately after death, and to capture small arterial networks a quality digital camera was used and the sectioned images were post-processed. Resultantly, highquality sectioned images in true color were obtained. The real body color images obtained accurately shown the colors of structure, for example, the gray matter of the cerebrum appeared reddish and not gray (Figs. 2 and 3).

Second, we experimented in a large laboratory in order to create well-aligned sectioned images of constant brightness. The researchers that produced the CVH and $\mathrm{VCH}$ wanted to be able to work throughout the year to produce sectioned images of various human, and therefore, built a freezing room, which for practical reasons had to be small. Thus, a small cryomacrotome was installed and the camera and strobe were attached to the cryomacrotome (Tang et al.; Yuan et al.; Zhang et al.). Unfortunately when the cadaver was ground, vibration from the cryomacrotome affected the camera and strobe, and this prevented the production of well-aligned images of consistent brightness. In the present study, we used a larger laboratory to prevent vibrational problems, and consequently well-aligned sectioned images of consistent brightness could be created although we experimented only in winter because of not freezing room.

Third, we used a heavy cryomacrotome in order to obtain sectioned images at constant intervals. When a cadaver is ground serially, it can be shaken by the rotary power of the cutting disc and moving power of the embedding box. Furthermore, if the cryomacrotome shakes, cadaver in the embedding box cannot be ground at constant thickness. Therefore, in the present study, we used a heavy (15 ton) and precise $(0.001 \mathrm{~mm}$ error tolerance) cryomacrotome, which was manufactured during a previous research study (Park et al., 2005a). 


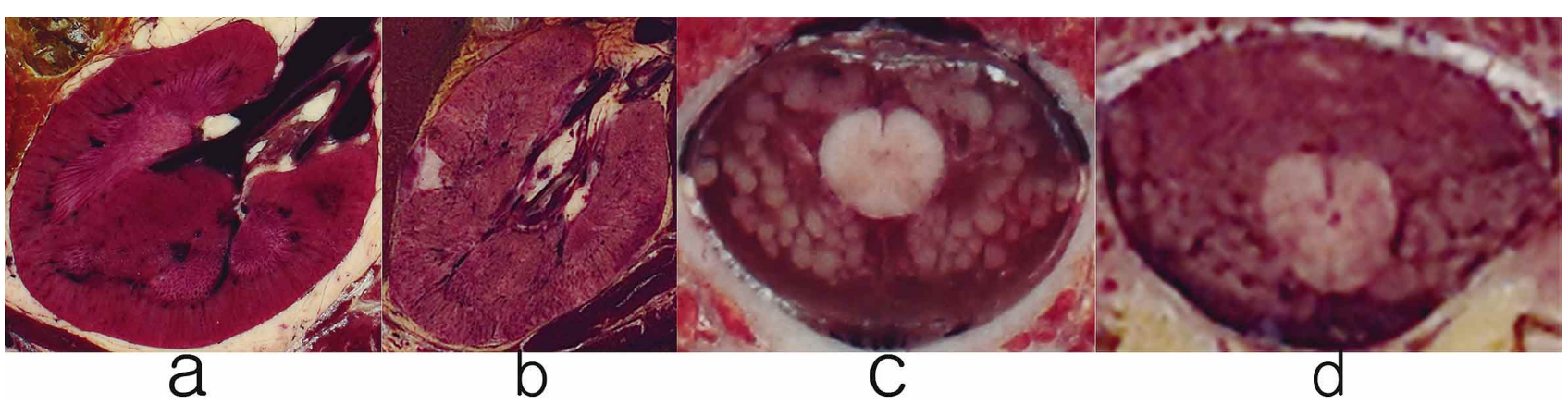

Fig. 6. Female (the present study) and male (our previous study) sectioned images of the Visible Korean (VK). a) Renal cortex and renal column of the kidney and c) cauda equina in female sectioned images of the present study are more vivid than b); d) in male images produces during our previous study (Park et al., 2006, 2009).

To produce sectioned images better than those produced in our previous research (VK) (Park et al., 2005a, 2009, 2010), we considered the following.

The first consideration was the importance of the digital camera. In our previous research, we initially used a 5 mega pixel Kodak DCS 560 camera to photograph the whole male body in 2002 (Park et al., 2005a), and subsequently, we used a 12 mega pixel Canon 5D camera to photograph the male head in 2006 (Park et al., 2009) and the female pelvis in 2007. In the present study, a 21-mega pixel Canon EOS-1Ds Mark III camera was used to photograph the whole female body in 2010 . Thanks to the rapid evolution of digital cameras, we were able to create better-sectioned images than those produced in 2002 (Fig. 6). However, camera development continues and in the near future, digital camera may be able to take photographs with microscopic resolution. When this occurs, we will make newsectioned images.

The second concern was of the involvement of experts. For example, regarding the cleaning of sectioned surfaces after grinding, if frost or residue is not removed from the ground surface cleanly and quickly they are photographed. Furthermore, if image post-processing is not performed by an expert, inconsistent alignments and image brightness can be expected. Our research team began preliminary experiments in 2000, and they are still working together; consequently, have become experts at such tasks. As a result of their work we were able to create state-of-art sectioned images (Figs. 2 and 3).

The applicability of the sectioned images produced was also confirmed. Browsing software was developed to explore freely sectioned and segmented images and to provide the names of structures. We believe that this browsing software could be used for teaching and learning sectional anatomy (Shin et al., 2011). In addition, by using segmented images, we built a PDF file in which surface models can be freely explored using Adobe Reader. In our opinion, this PDF file could be used for virtual dissection and virtual surgical operations (Park et al., 2013). During the course of this study, we developed browsing software and PDF files for 27 structures (Figs. 2, 3 and 4). It is our intention to expand this to other structures in the future. It is hoped that the sectioned images and surface models produced during this research become a useful source of medical software, because our goal is to produce data and data processing systems that contribute to the education of basic and clinical medicine. Recently, our data were used in the Anatomage Table $^{\mathrm{TM}}$ (Copyright 2005@ Anatomage, USA) of Anatomage (http://www.anatomage.com), which offers a life-size interactive anatomy visualization table for use by the medical community (Chung et al., 2015).

\section{ACKNOWLEDGEMENTS}

This work (2012R1A2A2A01012808) was supported by Mid-career Researcher Program through NRF grant funded by the MEST.

PARK, H. S.; CHOI, D. H. \& PARK, J. S. Mejoramiento de imágenes seccionadas y modelos de superficie del cuerpo femenino completo. Int. J. Morphol., 33(4):1323-1332, 2015.

RESUMEN: El objetivo fue presentar imágenes seccionadas en alta calidad de un cuerpo femenino que sería de gran ayuda en la creación de un atlas, en la disección virtual y en diversas aplicaciones para la educación médica y los ensayos clínicos; además, se trata de demostrar la aplicabilidad de las imágenes seccionadas. Un cadáver de sexo femenino fue seccionado en serie utilizando un criomicrótomo y luego fue fotografiado. Las estructuras en las imá- 
genes fueron segmentadas para producir imágenes en Photoshop. En un programa de navegación de desarrollo propio se almacenaron las imágenes seccionadas y segmentadas. Basado en las imágenes segmentadas, los modelos de superficie fueron construidas en el programa y guardadas como archivo PDF. Las imágenes seccionadas de alta calidad del cuerpo femenino fueron tomadas con intervalos entre 0,2 o $1 \mathrm{~mm}$; tamaño en píxeles de $0,1 \mathrm{~mm}$ y profundidad de color de 48 bits). En las imágenes obtenidas, las estructuras muy pequeñas y complicadas pudieron ser identificadas a color en el cuerpo. Con el fin de determinar la aplicabilidad de las imágenes, se produjo un programa de navegación que incluye imágenes seccionadas y segmentadas y el archivo PDF que incluye modelos de superficie. Las imágenes seccionadas y los modelos de superficie producidos durante esta investigación demostraron ser una fuente útil como programa médico. Todos los datos generados se encuentran disponibles gratuitamente.

KEY WORDS: Imagen de cuerpo completo; Anatomía seccionada; Mujer; Imagen tridimensional; Proyecto humano visible.

\section{REFERENCES}

Ackerman, M. J. The Visible Human Project: a resource for education. Acad. Med., 74(6):667-70, 1999.

Cho, Z. H. 7.0 Tesla MRI Brain Atlas. In Vivo Atlas with Cryomacrotome Correlation. New York, Springer, 2009.

Cho, Z. H.; Calamante, F. \& Chi, J. G. 7.0 Tesla MRI Brain White Matter Atlas. Seoul, Panmun Book Company, 2012.

Chung, B. S.; Shin, D. S.; Brown, P.; Choi, J. \& Chung, M. S. Virtual dissection table including the Visible Korean images, complemented by free software of the same data. Int. J. Morphol., 33(2):440-5, 2015.

Dai, J. X.; Chung, M. S.; Qu, R. M.; Yuan, L.; Liu, S. W. \& Shin, D. S. The Visible Human Projects in Korea and China with improved images and diverse applications. Surg. Radiol. Anat., 34(6):527-34, 2012.

Kim, C. H.; Choi, S. H.; Jeong, J. H.; Lee, C. \& Chung, M. S. HDRK-Man: a whole-body voxel model based on highresolution color slice images of a Korean adult male cadaver. Phys. Med. Biol., 53(15):4093-106, 2008.

Park, H. S.; Chung, M. S.; Shin, D. S.; Jung, Y. W. \& Park, J. S. Accessible and informative sectioned images, color-coded images, and surface models of the ear. Anat. Rec. (Hoboken), 296(8):1180-6, 2013.

Park, J. S.; Chung, M. S.; Hwang, S. B.; Lee, Y. S.; Har, D. H. \& Park, H. S. Visible Korean human: improved serially sectioned images of the entire body. IEEE Trans. Med. Imaging, 24(3):352-60, 2005a.
Park, J. S.; Chung, M. S.; Hwang, S. B.; Lee, Y. S. \& Har, D. H. Technical report on semiautomatic segmentation using the Adobe Photoshop. J. Digit. Imaging, 18(4):333-43, 2005b.

Park, J. S.; Chung, M. S.; Hwang, S. B.; Shin, B. S. \& Park, H. S. Visible Korean Human: its techniques and applications. Clin. Anat., 19(3):216-24, 2006.

Park, J. S.; Chung, M. S.; Shin, D. S.; Har, D. H.; Cho, Z. H.; Kim, Y. B.; Han, J. Y. \& Chi, J. G. Sectioned Images of the Cadaver Head Including the Brain and Correspondences With Ultrahigh Field 7.0 T MRIs. Proc. IEEE, 97(12):1988-96, 2009.

Park, J. S.; Chung, M. S.; Chi, J. G.; Park, H. S. \& Shin, D. S. Segmentation of cerebral gyri in the sectioned images by referring to volume model. J. Korean Med. Sci., 25(12):1710$5,2010$.

Quackenbush, D.; Ratiu, P. \& Kerr, J. Segmentation of the Visible Human datasets. The Visible Human Project Conference Proceedings, October 7-8, 1996.

Schiemann, T.; Freudenberg, J.; Pflesser, B.; Pommert, A.; Priesmeyer, K.; Riemer, M.; Schubert, R.; Tiede, U. \& Höhne, K. H. Exploring the Visible Human using the VOXEL-MAN framework. Comput. Med. Imaging Graph., 24(3):127-32, 2000.

Shin, D. S.; Chung, M. S.; Lee, J. W.; Park, J. S.; Chung, J.; Lee, S. B. \& Lee, S. H. Advanced surface reconstruction technique to build detailed surface models of the liver and neighboring structures from the Visible Korean Human. J. Korean Med. Sci., 24(3):375-83, 2009.

Shin, D. S.; Chung, M. S.; Park, H. S.; Park, J.S. \& Hwang, S. B. Browsing software of the Visible Korean data used for teaching sectional anatomy. Anat. Sci. Educ., 4(6):327-32, 2011.

Shin, D. S.; Jang, H. G.; Hwang, S. B.; Har, D. H.; Moon, Y. L. \& Chung, M. S. Two-dimensional sectioned images and threedimensional surface models for learning the anatomy of the female pelvis. Anat. Sci. Educ., 6(5):316-23, 2013.

Shin, D. S.; Jang, H. G.; Park, J. S.; Park, H. S.; Lee, S. \& Chung, M. S. Accessible and informative sectioned images and surface models of a cadaver head. J. Craniofac. Surg.23(4):1176-80, 2012a.

Shin, D. S.; Park, J. S.; Park, H. S.; Hwang, S. B. \& Chung, M. S. Outlining of the detailed structures in sectioned images from Visible Korean. Surg. Radiol. Anat., 34(3):235-47, 2012 b.

Spitzer, V.; Ackerman, M. J.; Scherzinger, A. L. \& Whitlock, D. The visible human male: a technical report. J. Am. Med. Inform. Assoc., 3(2):118-30, 1996.

Spitzer, V. M. \& Scherzinger, A. L. Virtual anatomy: an anatomist's playground. Clin. Anat., 19(3):192-203, 2006. 
Spitzer, V. M.; Whitlock, D. G. \& National Library of Medicine (U.S.). Atlas of the Visible Human Male: Reverse Engineering of the Human Body. Massachusetts, Jones \& Bartlett Publishers, 1998.

Spitzer, V. M. \& Whitlock, D. G. The Visible Human Dataset: the anatomical platform for human simulation. Anat Rec., 253(2):49-57, 1998.

Tang, L.; Chung, M. S.; Liu, Q. \& Shin, D. S. Advanced features of whole body sectioned images: Virtual Chinese Human. Clin. Anat., 23(5):523-9, 2010.

Yuan, Y.; Qi, L. \& Luo, S. The reconstruction and application of virtual Chinese human female. Comput. Methods Programs Biomed., 92(3):249-56, 2008.

Zhang, S. X.; Heng, P. A. \& Liu, Z. J. Chinese visible human project. Clin. Anat., 19(3):204-15, 2006.

\section{Correspondence to: \\ Jin Seo Park \\ Department of Anatomy \\ Dongguk University School of Medicine \\ 87 Dongdae-ro, Gyeongju, 780-350 \\ REPUBLIC OF KOREA}

Tel: +82-54-770-2402

Fax: +82-54-770-2402

Email: park93@dongguk.ac.kr

Received: 09-07-2015

Accepted: 04-08-2015 